\title{
INFLUENCE OF REPAINTING ON THE MECHANICAL PROPERTIES, SURFACE TOPOGRAPHY AND MICROSTRUCTURE OF POLYESTER POWDER COATINGS
}

\author{
Mirosław Szala', Edyta Agnieszka Kot ${ }^{2}$ \\ 1 Department of Materials Engineering, Mechanical Engineering Faculty, Lublin University of Technology, \\ Nadbystrzycka 36 Str., 20-618 Lublin, Poland, e-mail: m.szala@pollub.pl \\ 2 Mechanical Engineering Faculty, Lublin University of Technology, Nadbystrzycka 36 Str., 20-618 Lublin, Poland
}

Received: 2017.02.11

Accepted: 2017.03.21

Published: 2017.06.01

\begin{abstract}
The literature does not provide a systematic analysis of the effect of electrostatic powder coating repainting of structural and constructional aluminum elements on their technological parameters. It is industrial practice that worn or damaged coatings be repainted. It is crucial to determine the effect of electrostatic sprayed coatings repainting on their microstructure, roughness and mechanical properties. The aim of the work is to determinate the influence of repainting of powder deposited polyester coatings on their mechanical properties, roughness and microstructure. This study examined three different electrostatic spray epoxy coatings with matt, silk gloss and fine structure-matt finish. Test panels were prepared as single- and double-layer paint coatings on the aluminum alloy 6060 substrate. Hence, six test sets of coatings were deposited. Each set contained six samples. The microstructure of the cross section of coating was investigated by scanning electron microscopy (SEM) and light optical microscopy (metallographic and stereoscopy microscope). The chemical composition of coating was analyzed by the SEM-EDS method. The 2D surface roughness of single- and double-layer coatings and $3 \mathrm{D}$ surface topography maps were examined using a profile measurement gauge. The mechanical properties of coatings were measured by cupping, bending, impact, adhesion to substrate tests run according to standard procedures. As a result, the influence of repainting of polyester powder coatings on their properties was determined. The results demonstrate that repainting has no effect on the microstructure and coating adhesion to substrate as well as the bending test results and roughness of matt and silk gloss coatings. It has been found that repainting affects the results of impact and cupping tests as well as the roughness of samples with fine structure surface finish.
\end{abstract}

Keywords: electrostatic powder spraying, microstructure, polyester resin, organic coating, mechanical properties, repainting, roughness parameter, powder coating.

\section{INTRODUCTION}

Organic coatings are complex mixtures of chemical substances that can be grouped into four broad categories: binders, volatile components, pigments and additives. Binder polymers and their precursors are often called resins. The binder shapes to a large extent the properties of the coating film [9]. Resin types widely used in the coating industry are acrylics, epoxies, ure- thanes and polyesters. Polyester powder coatings are extensively used as architectural coatings, especially as protective and decorative films in outdoor applications $[3,4,9,18]$. The powder coating process does not use volatile organic solvents. Jing et al. [6] claim that powder coating with no emission of volatile organic compounds is a clean process. The process has attracted special due to the implementation of stricter environmental regulations and its superior performance in many 
aspects when compared to liquid coatings. Moreover, the main advantages of powder coating include powder recyclability close to $100 \%$, which can be reached by reclaiming over-sprayed powders with special equipment $[1,6,7,15]$.

The literature of the subject regularly reports information about systematic improvement of organic coatings and the development of the coating application technology $[8,12,15,18]$. Polyester powder coatings are typically applied on metallic substrates by electrostatic spray deposition (electrostatic powder spraying). Moreover, coatings with different types of surface finish such as matt, silk gloss and fine structure finish are usually applied to structural and constructional aluminum elements.

Electrostatic sprayed organic coatings are tested and evaluated according to ISO standards, in practice [18]. The quality of deposited manufacture relies on coating technological properties. Crucial factors include film-substrate adhesion, hardness, impact resistance, cracking and detached properties, elasticity, thickness and gloss. Particularly in the industry, the production of coatings with desired and repeatable properties coatings needs to be investigated [5, 14, 17]. The specialist literature also reports the studies investigating production process parameters, resistance to corrosion or wear, morphology, adhesion to substrate of powder coatings by different test methods [2, 13, 16, 17].

In specific coating applications, insufficient properties of coatings are enhanced by means of repainting. However, the influence of repainting on the properties of polyester powder coatings has not been systematically investigated. Hence, it is crucial to determine the effect of electrostatic sprayed coatings repainting on their technological properties.

The aim of this work was to determine the effect of repainting on the mechanical properties, topography and microstructure of polyester resin-based coatings.

\section{MATERIALS AND METHODS}

\section{Preparation of test samples}

The tests were performed on coated panels with dimensions 1 × 50 × $200 \mathrm{~mm}$ prepared by means of electrostatic powder spraying. The measured roughness of a substrate was $\mathrm{Ra}=0.23 \mu \mathrm{m}$ and $\mathrm{Rz}=1.65 \mu \mathrm{m}$. Aluminum alloy (AlMgSi) EN AW-6060 substrates were alkaline degreased, etched and conversion treated. Three commercial polyester resin-based powders were used: samples no. 1.1 and 1.2 were made from IGP-DURA $®$ face 5803, samples no. 2.1 and 2.2 from IGP-DURA $®$ face 5807; samples no. 3.1 and 3.2 from TIGER Drylac ${ }^{\circledR}$ Series 29 . Six sets of test panels were sprayed with each powder resin as single- and double-layer paint coatings on aluminum substrate. Each set contained six samples. The thickness of coatings was measured with the PosiTest DFT Combo ultrasonic thickness gauge according to PN-EN 2306. The description of test panels is given in Table 1.

\section{Research methods}

To identify the impact of repainting on the mechanical properties, roughness and microstructure of polyester resin coatings, the study investigated the structure and technological properties of test panels. Coating microstructure was examined in the cross section of samples by light optical microscopy (LOM) using the Nikon Eclipse MA200 microscope for brightfield observations as well as the Phenom World ProX microscope for scanning electron microscopy (SEM), with back-scatter electron mode with $10 \mathrm{kV}$ accelerating voltage of electron beam penetration. A chemical analysis of different coatings structure phases by the SEM-EDS method was conducted.

Coating roughness was measured using the SURTRONIC $3+$ profilometer in accordance to

Table 1. Samples description and selected properties of coatings

\begin{tabular}{|c|c|c|c|c|c|c|}
\hline $\begin{array}{l}\text { Coating } \\
\text { number }\end{array}$ & Sample description & Layer & Coating thickness $[\mu \mathrm{m}]$ & $\begin{array}{c}\text { Structure of } \\
\text { coating finish }\end{array}$ & Colour RAL & $\begin{array}{c}\text { Glance according } \\
\text { to EN ISO } 2813\end{array}$ \\
\hline \multirow{2}{*}{1} & 1.1 & 1 & $60-110$ & \multirow{2}{*}{ Matt } & \multirow{2}{*}{7016} & \multirow{2}{*}{$25-35 \mathrm{GU}$} \\
\hline & 1.2 & 2 & $130-210$ & & & \\
\hline \multirow{2}{*}{2} & 2.1 & 1 & $60-90$ & \multirow{2}{*}{ Silk gloss } & \multirow{2}{*}{7016} & \multirow{2}{*}{$65-85 \mathrm{GU}$} \\
\hline & 2.2 & 2 & $100-150$ & & & \\
\hline \multirow{2}{*}{3} & 3.1 & 1 & $60-140$ & \multirow{2}{*}{$\begin{array}{l}\text { Fine structure, } \\
\text { matt }\end{array}$} & \multirow{2}{*}{9004} & \multirow{2}{*}{ non-measurable } \\
\hline & 3.2 & 2 & $170-260$ & & & \\
\hline
\end{tabular}


PN-EN ISO 3274, 4284 and 4288. The topography of coatings was examined using the Hommel-Etamic 3D T8000 RC 120-400 profilometer. The roughness parameters $\mathrm{Ra}$ - arithmetic mean value of roughness and $\mathrm{Rz}$ - maximum height of the profile were measured according to the ISO 4287 standard.

The mechanical properties of paint coatings were investigated with accordance with the standards specially dedicated to the testing of paints and varnishes, especially under industrial conditions. Four mechanical tests were selected: adhesion measurement (acc. to PN-EN ISO 2409) - the resistance of paint coatings to separation from substrates, when a right-angle lattice pattern is cut into the coating, penetrating through to the substrate, $2 \mathrm{~mm}$ spacing between each 6 lattices; cupping test (acc. to PN-EN ISO 1520) by gradually increasing the depth of indentation to determine the minimum depth at which the coating cracks and/or becomes detached from the substrate, indicator radius $-10 \mathrm{~mm}$; impact test (acc. to PN-EN ISO 6271-1), with an energy of $2.5 \mathrm{Nm}$ and an impactor diameter of $15.9 \mathrm{~mm}$; and bending test (acc. to PN-EN ISO 1519) using a $5 \mathrm{~mm}$ mandrel. The properties of polyester coatings after mechanical testing were examined by both the unaided eye as well as viewing lens and a stereoscope microscope Nikon SMZ 1500.

\section{RESULTS AND DISCUSSION}

\section{Microstructure}

Figs. 1a and b compare the single- and double-layer coatings obtained by LOM. Fig. 2 shows the SEM images of the investigated coatings. One can observe in Figs. 1 and 2 that the microstructure of samples 1 and 2 is free from any nonuniformities such as pores or cavities. Coatings 3.1 and 3.2 reveal the presence of pores at the matrix-particle interface (Fig. 2c). This points to incomplete particle wetting by the polyester resin in the structure of sample 3 . The coating-substrate interface is uniform with a sufficient adherence of the polyester resin-based coating to the aluminum substrate. The results of LOM and SEM examination indicate that each layer of the double-layer coating is integral and forms a uniform coating.

The SEM observations reveal a heterogeneous structure of organic powder coatings. Two

\section{a)}

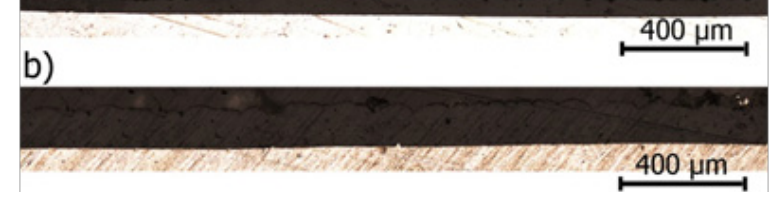

Fig. 1. Cross section of silk gloss surface finish coatings: a - sample no. 2.1, b - sample no. 2.2 (LOM)

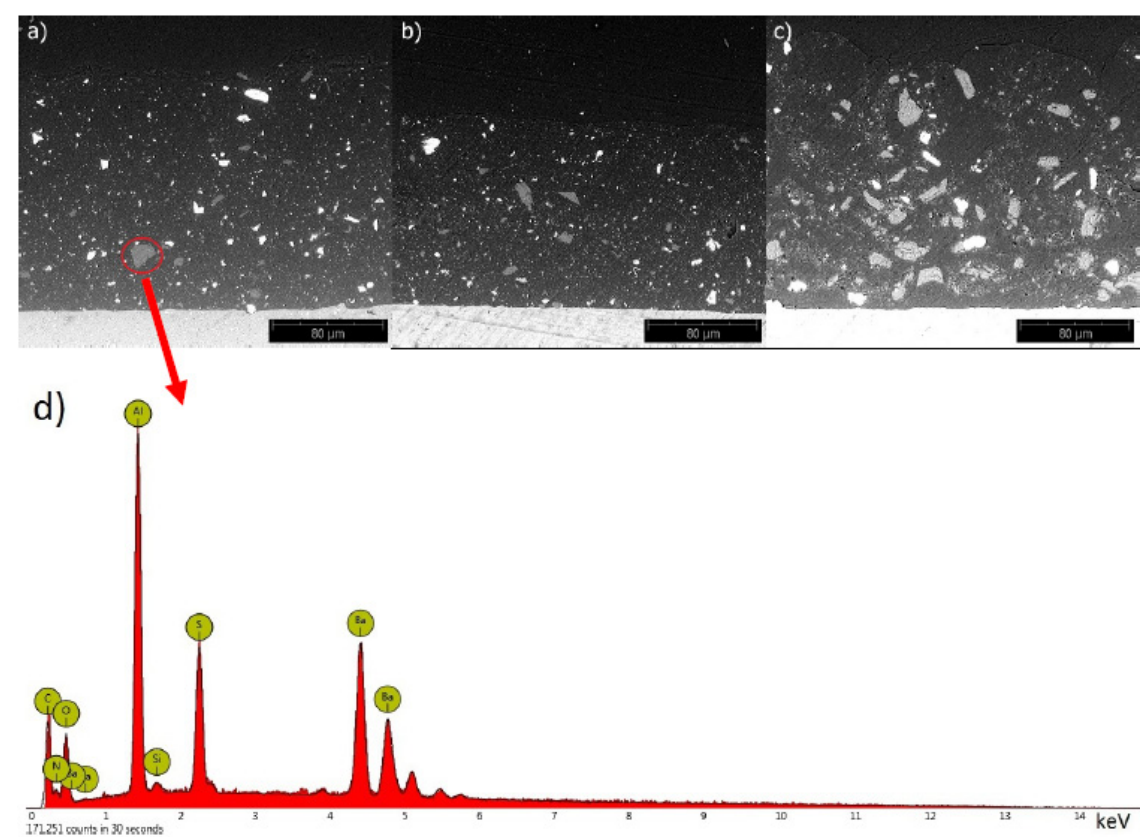

Fig. 2. Cross section of double-layer coatings: $\mathrm{a}-1.2, \mathrm{~b}-2.2, \mathrm{c}-3.2$ and $\mathrm{d}-$ results of chemical composition analysis of photography "a" circled area, SEM-EDS 

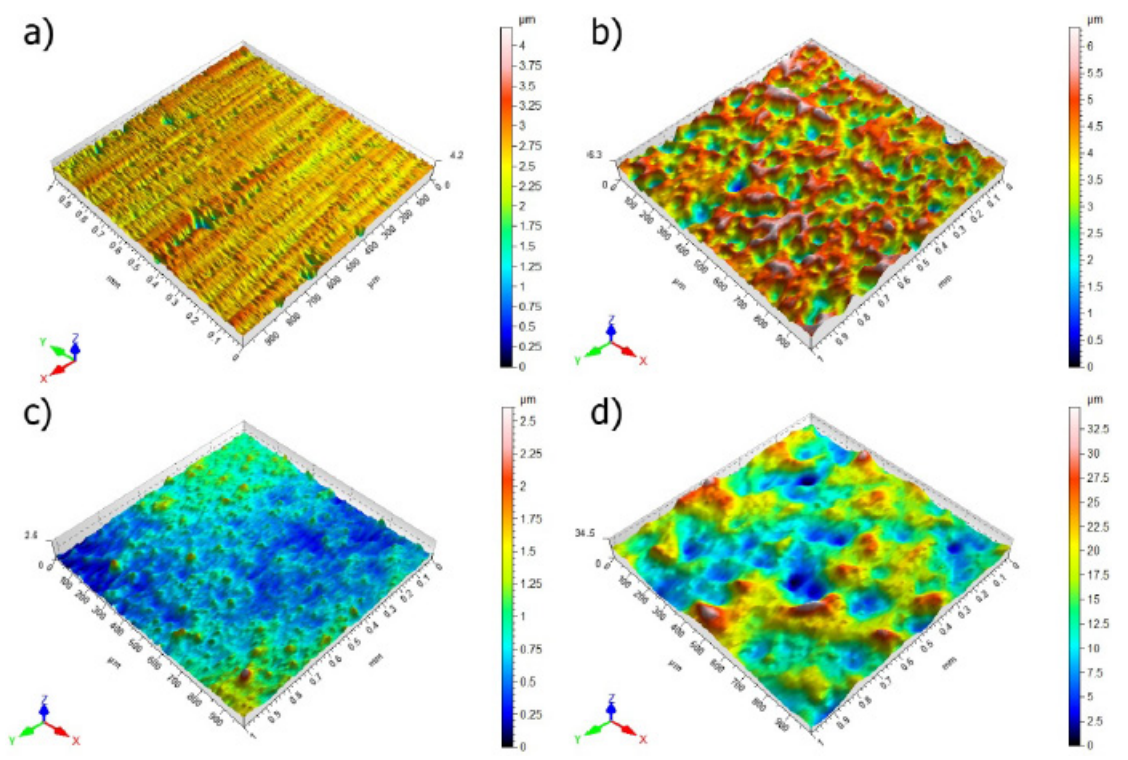

Fig. 3. Topography of aluminum substrate (a) and polyester coatings: b - sample no. 1.1, c - sample 2.1, $\mathrm{d}$ - sample no. 3.1

predominant phases can be identified in Figs. 2a, $\mathrm{b}$ and $\mathrm{c}$, the darkest phase being polymeric resin (binder) and the clearest one (particles) corresponding to pigments or additives. These results resemble the structure described in [17]. The SEM-EDS chemical spot analysis of particles reveals the presence of $\mathrm{C}, \mathrm{O}, \mathrm{N}, \mathrm{S}, \mathrm{Si}, \mathrm{Al}$ and $\mathrm{Ba}$ (Figs. 2c and d). It is established that these particles consist of inert pigments such aluminum silicates, barium sulfate, silicon dioxide, as reported in the literature $[9,20]$. As shown in the SEM microscopic image (Fig. 2), the size of particles in inter pigments ranges up to $20 \mu \mathrm{m}$.

\section{Roughness and topography}

The surface morphology of polyester resin power coatings was investigated using $3 \mathrm{D}$ and 2D profilometer, Fig. 3 and Fig. 4 respectively. The level plot graphs of substrate and coatings with different types of surface finish are shown in Fig. 3. The examination of substrate topography indicates a typical lay of surface finish (Fig. 3a) resulting from the production process of metal sheet. Samples with different types of coatings are shown in Figs. 3b-d. Paint coatings have a non-directional surface finish as reported in the literature $[2,15,19]$. Coating 2.1 exhibits a smoother surface and its roughness is lower than that of aluminum substrate.

The level plot graphs in Fig. 3 show greater variations in elevation of different types of coatings (samples 1, 2 and 3). The highest scatter of results between the bottom and top of the surface was observed for sample 3.1 and it amounted up to $32.5 \mu \mathrm{m}$. In sample 3 , the areas of deep valley and hills are visible, and a great number of bulges can be observed too. Therefore, the surface topography of sample 3.1 is less uniform than the topography of sample 2.1. After repainting, these features develop, as can be observed in Fig. 4. Moreover, sample 3 has the highest average roughness parameters $\mathrm{Ra}$ and $\mathrm{Rz}$ - their values are five times higher than those of coating 1.1 , and more than ten times higher than those of coating 2.1 coating (Fig. 4 ).

The tested polyester coatings have various types of surface finish (matt, silk gloss and fine structure, matt). Hence, one can observe the influence of paint coating structure on coating roughness after repainting. The roughness parameters plotted in Fig. 4 clearly indicate that repainting does not

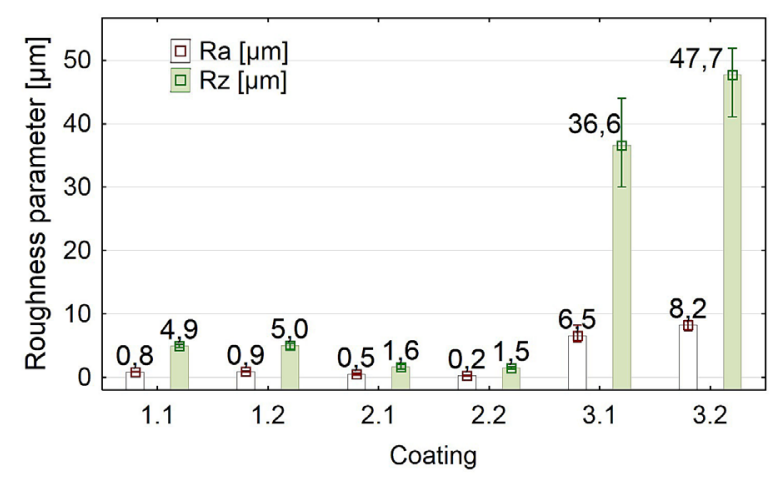

Fig. 4. Influence of repainting on roughness of polyester coatings 


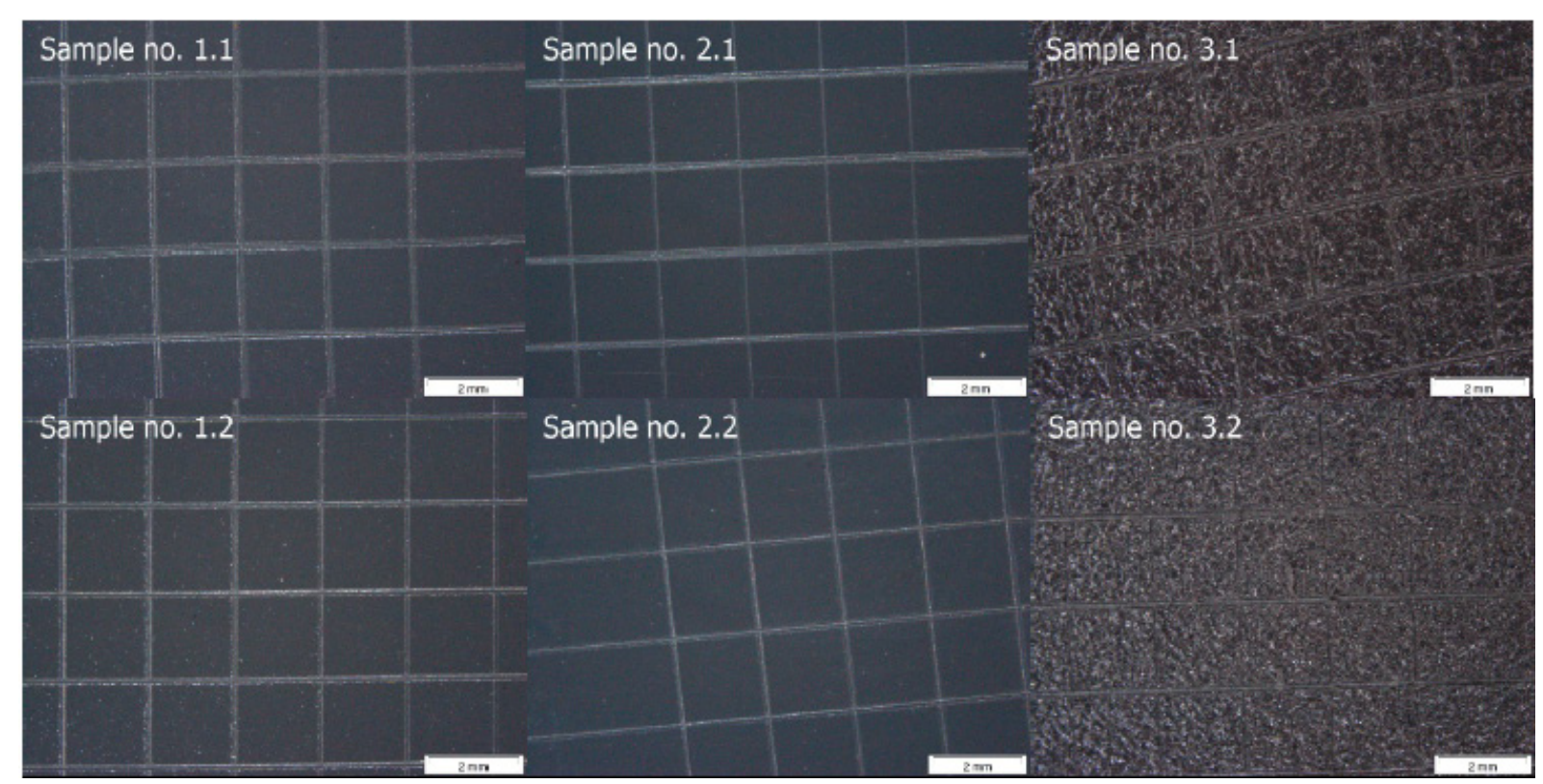

Fig. 5. Examined areas of single-layer and double-layer coatings after cross-cut test: single-layer (top), doublelayer coatings (down), stereoscope microscope

significantly affect the morphology of samples 1 and 2, whereas the surface roughness parameters Ra and Rz of sample 3 increase by about $25 \%$.

\section{Adhesion and mechanical testing}

Cracking and/or detachment from the substrate under different conditions of deformation include adhesion, cupping, bending and impact testing. The adhesion of coating to substrate depends on factors such as the adhesive force between the surface layer of a component and a coating, metal surface wettability, free energy, surface roughness and the presence of polar groups [9, 19, 20]. Moreover, sophisticated methods like ozone treatment can be applied to increase adhesion bonding between polymer material and various metal substrates $[10,11]$. Fig. 5 shows the photographs of six samples after adhesion testing.

The cross-cut test results demonstrate a high adhesion of single- and double-layer polyester coatings. The edges of the cuts are completely smooth, without separation or detachment on the intersections of the lattice, even when examined under a magnifier. Hence, repainting does not influence the adhesion to substrate of polyester paint coatings.

The cupping test was run until the coatings began to crack and/or became detached from the substrate. Fig. 6 shows the cupping test results. K. Zinowicz and K. Gauda in the work [20] claim that there is a relationship between cupping test results and the elasticity and adhesion of coatings.
Repainting has a positive effect on matt (no. 1) and gloss finish coatings (no. 2), whereas the worst cupping test results were produced by the fine structure coatings (Fig. 6). The lowest value of indentation was obtained for fine structure matt coatings (no. 3.2). The cupping test results reveal that the application of matt and silk gloss finish single-layer (1.1 and 2.1) and double-layer coatings (1.2 and 2.2) leads to an increase in the depth of indentation. Repainting decreases the elasticity of coatings made from powder no. 3 .

The bending test results reveal that negative results were obtained only for fine structure samples, both single-layer (3.1) and double-layer (3.2). Therefore, it can be concluded that repainting does not have an impact on bending results.

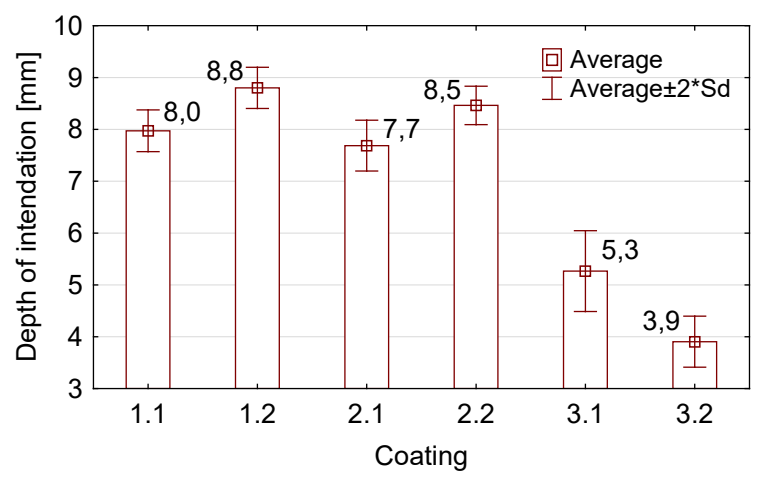

Fig. 6. Cupping test results. Minimum depth at which the coating cracks and/or becomes detached from the substrate 

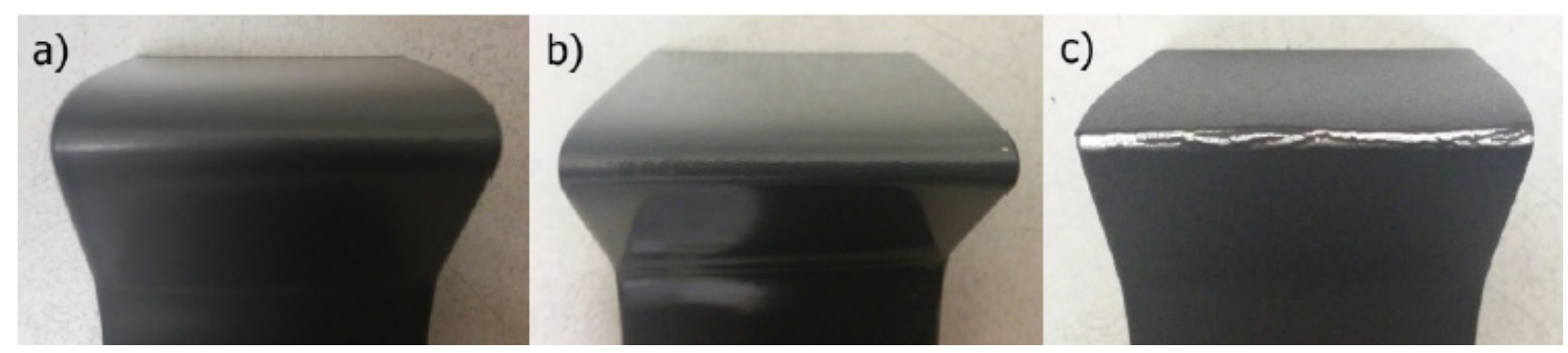

Fig. 7. Test panels of double-layer coatings after bending test: a - sample no. 1.2, b-sample no. 2.2, c- sample no. 3.2

Fig. 7 shows the bending test results of doublelayer coatings. Cracking and detachment from the substrate under bending deformation is clearly visible for samples 3.2 but not for samples 1.2 and 2.2. The presence of pores in the microstructure of samples 3.2 may have a strong influence on coating delamination during the bending test.

Fig. 8 shows the photographs of the samples after the impact test examined with a stereoscope microscope. One can observe differences in the behavior of the two tested sets of coatings. Single-layer coatings produce positive results in the impact test results, unlike double-layer coatings. The results show a relationship between tenacity and repainting. Thicker coatings do not pass the impact test, which means that repainting has a negative influence on the impact test results. The repainted samples exhibit cracking and disclose of the aluminum substrate (samples 1.2, 2.2 and $3.2)$ in the area impacted, Fig. 8.

\section{CONCLUSIONS}

Repainting is applied when the properties of a coating are insufficient for a given coating application. Moreover, it may be necessary to apply surface finish types such as matt or silk gloss. This study investigated the influence of electrostatic repainting of three polyester resin coatings on their mechanical properties, topography and microstructure.

The repainting of coatings with different surface finish do not influence the microstructure of coatings. The interface between layers in not visible. The structure of polyester coatings of the tested matt (no. 1), silk gloss (no. 2) and fine structure matt (no. 3) consists of polyester epoxy resin (binder) and particle size range up to $20 \mu \mathrm{m}$ (inert pigments). These inert pigments consist of chemical elements that can form aluminum silicates, barium sulfate, silicon dioxide. The presence of

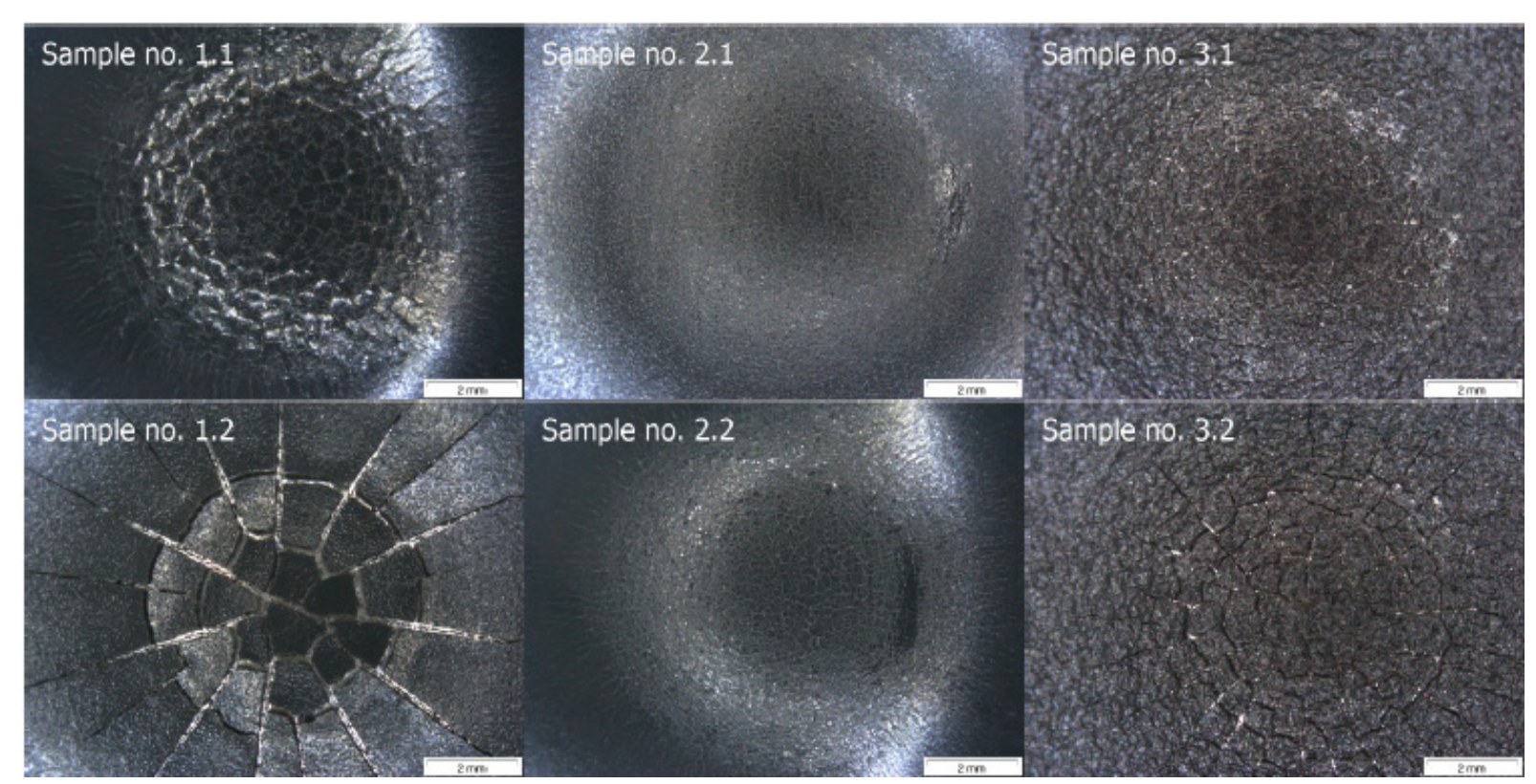

Fig. 8. Polyester powder coatings after impact test: single-layer coatings (top), double-layer coatings (down), stereoscope microscope 
pores at the matrix-particle interface was noticed only in single-layer structure coatings (sample 3.1) and double-layer coatings (sample 3.2).

Differences in the morphology and roughness parameters of the tested coating surface finish can be observed. Also, the roughness parameters $\mathrm{Ra}$ and $\mathrm{Rz}$ of repainted fine structure coatings (no. 3) increased by about $25 \%$, while the roughness parameters Ra and Rz of matt (no. 1) and silk gloss (no. 2) repainted coatings did not change significantly.

Repainting affects coating thickness which is crucial in terms of material properties. The samples coated by fine structure matt film (no. 3) produced the worst results in the mechanical test. This is due to the presence of pores in their structure and their significant thickness. The samples with silk gloss finish (no. 2) have a thicker film. However, the cross-cut test results point to a high adhesion of both single-layer as well as double-layer polyester coatings. Hence, repainting does not influence the adhesion to substrate of powder coatings. However, one can observe a relationship between impact resistance and repainting. Single-layer coatings do not pass the impact test, which means that repainting has a negative effect on impact test results.

A positive effect of repainting was observed for matt (no.1) and gloss finish coatings (no. 2), while the worst cupping test results were produced by fine structure coatings (no. 3). Repainting decreases the elasticity of coatings made from powder no. 3 (fine structure matt surface finish). The bending test results are negative only for fine structure coatings (no. 3), both single-layer and doublelayer. Therefore, it can be concluded that repainting does not exert impact on bending results.

\section{REFERENCES}

1. Bailey, A.G.: The science and technology of electrostatic powder spraying, transport and coating. Journal of Electrostatics. 45, 2, 85-120 (1998).

2. Barletta, M.: Combined use of scratch tests and CLA profilometry to characterize polyester powder coatings. Surface and Coatings Technology. 203, 13, 1863-1878 (2009).

3. Barletta, M. et al.: On the combined use of scratch tests and CLA profilometry for the characterization of polyester powder coatings: Influence of scratch load and speed. Applied Surface Science. 254, 22, 7198-7214 (2008).

4. Blicharski, M.: Inżynieria powierzchni. Wydawnictwo Naukowo Techniczne, Warszawa (2009).
5. Díaz-Benito, B. et al.: Mechanical properties of polyester films painted after silanization of 6063 aluminium alloy with different pretreatment conditions. Progress in Organic Coatings. 70, 4, 287-292 (2011).

6. $\mathrm{Fu}, \mathrm{J}$. et al.: Investigation of the recyclability of powder coatings. Powder Technology. 211, 1, 38-45 (2011).

7. Hu, R.-G. et al.: Recent progress in corrosion protection of magnesium alloys by organic coatings. Progress in Organic Coatings. 73, 2-3, 129-141 (2012).

8. Jelonek, A.: Malowanie farbami proszkowymi. Lakiernictwo przemysłowe. 3, 71, (2011).

9. Jr, Z.W.W. et al.: Organic Coatings: Science and Technology. John Wiley \& Sons (2007).

10. Kłonica, M. et al.: Polyamide 6 surface layer following ozone treatment. International Journal of Adhesion and Adhesives. 64, 179-187 (2016).

11. Kwiatkowski, M.P. et al.: Comparative Analysis of Energetic Properties of Ti6Al4V Titanium and ENAW-2017A(PA6) Aluminum Alloy Surface Layers for an Adhesive Bonding Application. Ozone: Science \& Engineering. 35, 3, 220-228 (2013).

12. Lenkiewicz, K.: Nakładanie powłok lakierniczych. Instytut Technologii Eksploatacji - Państwowy Instytut Badawcz, Radom (2006).

13. McKeen, L.W.: Fluorinated Coatings and Finishes Handbook: The Definitive User's Guide. William Andrew (2015).

14. Nechvílová, K., Kalendová, A.: Properties of organic coatings containing pigments with surface modified with a layer of $\mathrm{ZnFe} 2 \mathrm{O} 4$. Advances in Science and Technology Research Journal. Vol. 9, nr 28, (2015).

15. Ofat, I., Kozakiewicz, J.: Modification of epoxypolyester and polyester powder coatings with silicone-acrylic nanopowders - effect on surface properties of coatings. Polimery. 59, 09, 643-649 (2014).

16. Puig, M. et al.: Adhesion enhancement of powder coatings on galvanised steel by addition of organomodified silica particles. Progress in Organic Coatings. 77, 8, 1309-1315 (2014).

17. Puig, M. et al.: The combined role of inhibitive pigment and organo-modified silica particles on powder coatings: Mechanical and electrochemical investigation. Progress in Organic Coatings. 80, 11-19 (2015).

18. QUALICOAT: Home - QUALICOAT, http://www. qualicoat.net/main/home.html.

19. Sharifi Golru, S. et al.: Effects of surface treatment of aluminium alloy 1050 on the adhesion and anticorrosion properties of the epoxy coating. Applied Surface Science. 345, 360-368 (2015).

20.Zinowicz, Z., Gauda, K.: Powłoki organiczne w technice antykorozyjnej. Wydawnictwo Politechniki Lubelskiej (2003). 